\title{
educação

\section{A inclusão de estudantes surdos no ensino superior brasileiro: O caso de um curso de Pedagogia}

\author{
ISABEL RodRigues SANCHES \\ Universidade Lusófona de Humanidades e \\ Tecnologias, Portugal \\ Polliana Barboza da Silva ${ }^{\text {II }}$ \\ Faculdade Alpha, Brasil
}

O objetivo desta pesquisa é compreender o processo de inclusão dos estudantes surdos no curso de graduação em Pedagogia, no ensino superior brasileiro. Para atingir este objetivo, foi utilizada a entrevista semidiretiva a três estudantes surdos e a observação das aulas de três professores destes alunos. É uma investigação qualitativa, de natureza descritiva/interpretativa, que analisa os sujeitos no seu contexto e valoriza a interação que se estabelece entre eles. Verificou-se, através das percepções destes estudantes, que compreendem o paradigma da inclusão, conhecem os documentos orientadores, entendem e concordam com os princípios e as práticas que são propostas, mas levantam algumas questões e afirmam preferir as salas especiais para a aprendizagem. Observou-se que os estudantes surdos participam das aulas, dos trabalhos de grupo, procuram estar junto ao intérprete, para melhor compreenderem, procuram a interação com professores e colegas ouvintes; porém, o desconhecimento da língua de sinais (LIBRAS), por parte dos ouvintes, é uma das maiores barreiras para a inclusão. Estes estudantes gostam da perspetiva da inclusão, no que diz respeito a socializar com os ouvintes, e procuram contribuir para que essa socialização e a aprendizagem aconteçam, utilizando alternativas à LIBRAS para a comunicação. Constatam, porém, que é preciso um esforço coletivo, de surdos e ouvintes, para que o respeito pela diferença e pela identidade e cultura surda tenham maior expressão no contexto escolar.

Palavras-chave: Ensino superior; Estudante surdo; Inclusão; Brasil

\section{IN T RODUÇ ÃO}

Considera-se pessoa surda aquela que tem a compreensão do mundo por meio de experiências visuais, tendo uma cultura e língua - a Língua Brasileira de Sinais (LIBRAS), no caso do Brasil. Os surdos, vistos na perspetiva cultural, fazem parte de uma comunidade (a comunidade surda), apresentando identidade e língua próprias. A educação inclusiva procura atender às necessidades dos estudantes surdos, garantindo a sua participação nas diversas situações de aprendizagem, dentro e fora da sala de aula. De acordo com Sanches e Teodoro 
(2007), "numa escola inclusiva só pode existir uma educação inclusiva, uma educação em que a heterogeneidade do grupo não é mais um problema, mas um grande desafio à criatividade e ao profissionalismo dos profissionais da Educação" (p. 110). Enquanto professores, deparamo-nos com as salas de aulas repletas de pessoas, cada uma com a sua identidade, costumes, cultura, religião, vida própria, um autêntico "arco-íris" (Sanches, 2011b). A diversidade de experiências, de saberes e de culturas dos alunos é uma maisvalia geradora de novos conhecimentos, campo aberto para experienciar diferentes metodologias em que as aprendizagens sejam construídas com a mediação do professor, do grupo escolar e da família, valorizando as experiências e potencialidades de cada um.

O presente artigo dá conta de um estudo que procura compreender o processo de inclusão dos estudantes surdos, através das suas percepções e da sua atuação em sala de aula, no ensino superior, num curso de graduação em Pedagogia. Parte do pressuposto de que a educação inclusiva se preocupa em promover a participação dos estudantes e procura reduzir a exclusão, reestruturando culturas, políticas e práticas pedagógicas, nas instituições de ensino, respondendo continuamente à diversidade dos estudantes.

Neste estudo abordamos especificamente a educação inclusiva em contexto escolar, ressaltando a importância da Língua Brasileira de Sinais - LIBRAS (primeira língua dos surdos no Brasil). Após o enquadramento teórico, apresentamos os procedimentos metodológicos e, por fim, a análise e discussão dos resultados, com base em entrevistas com os estudantes surdos e em observações em sala de aula. Concluimos com algumas considerações finais.
1. A EDUCAÇÃO INCLUSIVA E A LínguA BRASILEIRA DE SINAIS NO ENSINOSUPERIOR BRASILEIRO

A educação inclusiva, de acordo com Stainback e Stainback (1999), "é a prática da inclusão de todos - independentemente de seu talento, deficiência, origem socioeconómica ou origem cultural - em escolas e salas de aula provedoras, onde todas as necessidades dos alunos são satisfeitas" (p. 21). Preconiza-se que a educação inclusiva aconteça nas instituições de ensino, procurando uma cultura de escola e de sala de aula que, partindo da diversidade como lema, tenha como objetivo primeiro o desenvolvimento global dos alunos (Correia, 2013). Procura atender às necessidades dos estudantes, garantindo a sua participação nas diversas situações de aprendizagem, dentro e fora da sala de aula, nas interações com os que fazem parte da escola, em ambientes propícios à aprendizagem, recorrendo a estratégias, materiais pedagógicos e recursos didáticos e tecnológicos pertinentes, adequados e oportunos (Colaço \& Sanches, 2013).

Para implementar a educação inclusiva, os professores podem fazer parcerias, participar em formações, planificar pensando na diversidade e nas oportunidades de aprendizagem de cada estudante, de forma a trabalhar as suas potencialidades, numa perspetiva de inclusão plena, ou seja, garantir o acesso, a permanência, o desenvolvimento e o sucesso de todos e de cada um (Patatas \& Sanches, 2017). Também Correia (2001) afirma que

O príncipio da inclusão apela, portanto, para a educação inclusiva que pretende, de um modo geral, que todos os alunos, com as mais diversas capacidades, interesses, características e necessidades, possam aprender juntos, que seja dada atenção ao seu desenvolvimento global (académico, socioemocional e pessoal), que, 
sempre que possível, todos os serviços educativos sejam prestados nas classes regulares, que se crie um verdadeiro sentido de igualdade de oportunidades (não necessariamente as mesmas oportunidades para todos) que vise o sucesso escolar. (p. 125)

A educação inclusiva requer de todos nós um esforço no que diz respeito à aprendizagem de todos os estudantes, promovendo o bem-estar académico, emocional e social, favorecendo assim o seu desenvolvimento global.

\subsection{A Língua Brasileira De Sinais}

A Língua Brasileira de Sinais (LIBRAS) “é uma língua visual-espacial articulada através das mãos, das expressões faciais e do corpo. É uma língua natural usada pela comunidade surda brasileira" (Quadros \& Karnopp, 2004, p. 19). A LIBRAS, assim como toda a língua, tem uma singularidade e especificidade ao nível de desenvolvimento cognitivo, de maturação e de aquisição de regras sociais. De acordo com Garcia (2015), "são as regras sociais, entendendo-a como o modo pelo qual a língua de sinais circulará entre os seus usuários, que darão à LIBRAS um caráter arbitrário" (p. 23).

A LIBRAS resiste às imposições de uma sociedade pensada e construída com base numa cultura ouvinte. Como os surdos precisam de comunicar, assim como os ouvintes, a LIBRAS é primordial para esta comunicação, pois ela é a primeira língua das pessoas surdas.

A Lei n. ${ }^{\circ}$ 10.436/2002, de 24 de abril, assegura às pessoas surdas a LIBRAS como sua primeira língua (L1), devendo os sistemas educacionais garantir o ensino da LIBRAS. De acordo com Garcia (2015), a Lei Federal 10.436/2002 representa um marco na educação brasileira, porque, reconhecendo uma língua de sinais brasileira, reconhece a sua legitimidade e a sua importância na cultura do surdo, na sua história e na sua cultura linguística e social. A
LIBRAS é reconhecida como sendo a língua oficial das comunidades surdas brasileiras e estas têm o direito de a usar como sua primeira língua.

\subsection{A INVESTIGAÇÃO SOBRE OS ESTUDANTES SURDOS: ALGUNS DESTAQUES DO ENSINO SUPERIOR B R A S I LEIRO}

O número de estudantes surdos que inicia um curso superior é cada vez maior no Brasil. De acordo com os dados do Ministério da Educação (MEC), no ano de 2003, 665 surdos frequentavam a universidade; em 2005, houve um aumento desse número para 2.428 nas instituições privadas e públicas (Brasil, 2006). Nos últimos anos houve um crescimento significativo no nível educacional dos surdos, sendo que o Censo da Educação Superior (2013) aponta um total de 8.676 alunos surdos, com deficiência auditiva ou surdos-cegos matriculados nas instituições de educação superior.

Esta presença dos estudantes surdos na universidade é bastante recente no Brasil e acontece devido a alguns elementos que, segundo Bisol, Valentini, Simioni, e Zanchin (2010), são:

O reconhecimento, a partir de meados da década de 1990, do status de língua para a língua de sinais; o desenvolvimento de propostas de educação bilíngue de qualidade para surdos; e um momento histórico no qual políticas públicas de inclusão vêm aos poucos aumentando o acesso e a participação ativa de pessoas com necessidades especiais em diferentes contextos sociais. (p. 148)

$\mathrm{O}$ aumento de estudantes surdos no ensino superior brasileiro tem originado trabalhos de investigação sobre a sua inclusão no ensino regular e o seu processo de aprendizagem. Destacamos em seguida aqueles que nos 
pareceram mais pertinentes de acordo com a temática que está a ser estudada.

Daroque (2011), ao trabalhar a temática "Alunos surdos no ensino superior: uma discussão necessária", discute as condições que são oferecidas aos estudantes surdos que frequentam o ensino superior, tendo por objetivo analisar, através de entrevistas individuais, os dizeres dos estudantes surdos e dos seus professores sobre os obstáculos e possibilidades que o surdo encontra no dia a dia da sala de aula. Os resultados desta pesquisa revelam que os obstáculos enfrentados são referentes à leitura eà escrita, por a escolarização anterior não ter sido eficaz, prejudicando assim a ampliação dos conhecimentos nesta etapa de estudos. Os estudantes surdos afirmam que alguns professores demonstram preconceitos e não têm informações sobre a surdez. Os professores, por sua vez, destacam que a dificuldade encontrada é a língua, pois a prática bilingue é ainda inexistente e não reconhecida no ensino superior.

Bisol et al. (2010), ao desenvolver a temática "Estudantes surdos no ensino superior: reflexões sobre a inclusão", tiveram como objetivo compreender a vivência universitária de estudantes surdos matriculados num curso de graduação. Estes foram inquiridos através de entrevistas semiestruturadas videogravadas. Estes estudantes frequentaram escolas especiais, identificam-se com a LIBRAS e com a cultura surda e dispõem de intérpretes. Os resultados desta pesquisa identificam os desafios dos estudantes surdos estudarem num espaço universitário construído para a comunidade ouvinte: a LIBRAS, o contato com o surdo e a valorização da cultura surda acabam por ser esquecidas. Destacam as dificuldades da passagem da língua de sinais à língua portuguesa e "a necessidade de manter referenciais identitários valorizados aos olhos dos ouvintes, além da importância de reorganizar as estratégias de ensino e de avaliar a participação do intérprete de língua de sinais" (Bisol et al., 2010, p. 147). Sobre os desafios enfrentados pelos estudantes surdos, estes autores afirmam: "estar em um ambiente, onde a surdez e a comunicação visual não são a regra, exige muito desses jovens" (Bisol et al., 2010, p. 169).

Ansay (2009), ao abordar "A trajetória escolar de alunos surdos e a sua relação com a inclusão no ensino superior", teve como objetivo investigar a trajetória educacional de estudantes surdos inseridos nas universidades de Curitiba, no estado do Paraná - Brasil. Os resultados mostraram que não é uma tarefa fácil para o estudante surdo estar no ensino superior, pois tem encontrado muitos desafios:

A falta de intérpretes, o despreparo dos professores, o preconceito e discriminação e a falta ou o uso inadequado do material didático pedagógico para este alunado, como por exemplo, filmes legendados, aulas sem material de apoio visual e o uso do power point na sala escura. (Ansay, 2009, p. 114)

A pesquisa constata ainda que o estudante surdo que ingressa no ensino superior almeja a capacitação profissional, sendo necessário valorizar o estudante surdo e proporcionarlhe condições para que possa avançar nos seus estudos. O grande desafio da universidade é mudar as suas práticas pedagógicas, de modo a dar resposta a todos os estudantes, independentemente das suas limitações. É necessário pensar em práticas pedagógicas que valorizem a heterogeneidade, a cultura surda e principalmente a língua das pessoas surdas, para que estas possam sentir-se parte integrante do espaço universitário.

Cruz e Dias (2009), ao abordar a temática “Trajetória escolar do surdo no ensino superior: condições e possibilidades", tiveram 
como objetivo conhecer as experiências dos estudantes surdos e as suas condições, ao nível do ensino superior, em três cidades da região norte do estado de São Paulo (Brasil). Participaram da pesquisa sete estudantes surdos e foram aplicadas 10 entrevistas presenciais, e 11 à distância, por meio de email e messenger. Cruz e Dias (2009) concluem que as condições dos alunos surdos no ensino superior são de "dificuldades, de impedimentos, de abandono e de rejeição" e que os "surdos são obrigados a se responsabilizarem por sua aprendizagem, priorizando o trabalho extra classe para recuperação de notas” (p. 65). Apesar dos impedimentos, os surdos são produtivos $\mathrm{e}$ interessados nos seus estudos. A dificuldade maior é a universidade ser organizada para ouvintes, não havendo a contemplação da LIBRAS.

Os estudos analisados revelam-nos que as dificuldades que os estudantes surdos enfrentam estão ligadas ao processo de ensino e aprendizagem, à leitura e à escrita, à cultura surda e à LIBRAS. Como os estudantes universitários em sua maioria são ouvintes, é necessário um trabalho de valorização da heterogeneidade, um investimento na formação dos professores, no que diz respeito à inclusão dos estudantes surdos, e a valorização da Língua Brasileira de Sinais. Ficou explícito também que é necessária a parceria com outros profissionais, principalmente com o intérprete de LIBRAS, em sala de aula.

\section{PROCEDIMENTOS METODOLÓGICOS}

Para podermos compreender o processo de inclusão destes estudantes surdos, considerando o que eles pensam e o que acontece na sala de aula, esta pesquisa tem uma abordagem qualitativa, de natureza descritiva/interpretativa. É a análise de uma situação específica, através do cruzamento da informação recolhida pelas técnicas utilizadas: a entrevista semiestruturada e a observação de classes.

Segundo Stake (2011), “a pesquisa qualitativa se baseia muito nas percepções interpretativas feitas durante todo o planejamento, a coleta de dados, a análise e a elaboração do texto do estudo" (p. 66). Segundo o mesmo autor, os métodos qualitativos permitem uma melhor compreensão dos processos escolares, de aprendizagem, de relações, dos processos institucionais e culturais, de socialização e sociabilidade, do cotidiano escolar em suas múltiplas implicações e das formas de mudança e resiliência presentes nas ações educativas, o que vem ao encontro dos objetivos a que nos propomos.

O estudo aqui apresentado é referente a três estudantes surdos que frequentam o curso de graduação em Pedagogia, numa instituição privada brasileira, há quatro anos, com o objetivo de ensinar crianças (Silva, 2015). São eles: ES1 com 32 anos de idade, ES2 com 33 anos e ES3 com 31 anos. Utilizámos a entrevista semiestruturada pois permite a utilização de uma "série de perguntas abertas feitas verbalmente em uma ordem prevista, mas na qualo entrevistador pode acrescentar perguntas de esclarecimento" (Laville \& Dionne, 2007, p. 188). A entrevista, como técnica de pesquisa, foi realizada numa conversa a dois, conforme nos propõe Minayo (2009), com "o objetivo de construir informações pertinentes para o objeto de pesquisa" (p. 64).

As entrevistas tiveram como ponto de partida um roteiro, construído e organizado para os estudantes surdos. Foi realizada previamente uma entrevista-piloto, a dois estudantes surdos do ensino superior da mesma instituição, não integrantes da pesquisa, com a finalidade de testar a compreensão, a pertinência dos blocos, a duração e a linguagem utilizada. Foram realizados os acertos sugeridos, em relação à linguagem e duração da entrevista. As 
perguntas foram organizadas em seis blocos, que serviram de ponto de partida para a definição das categorias de análise e respetivas subcategorias (Tabela 1).

As entrevistas foram gravadas em vídeo, com a permissão dos sujeitos participantes, sendo depois transcritas na íntegra. O texto resultante da transcrição das entrevistas foi submetido a uma análise de conteúdo, utilizando o modelo de Bardin (2006), cotejado com o de outros autores (Esteves, 2006; Estrela, 1986; Robert \& Bouillaguet, 1997). Foi feita uma primeira leitura flutuante de toda a informação transcrita, para verificar as possibilidades de análise. Tendo em conta a organização da informação, constante no guião da entrevista, o conteúdo expresso, o quadro teórico e os objetivos da pesquisa, foram levantadas duas categorias para análise: (1) o processo de inclusão dos estudantes surdos no ensino superior e (2) o processo de ensino e aprendizagem, depois subdivididas em subcategorias, resultantes da agregação das unidades de registo, tendo em conta os critérios enunciados por Bardin (2006): exclusão mútua, homogeneidade, pertinência e objetividade.

De acordo com os objetivos da pesquisa, no que respeita à necessidade de compreender o que se "faz" em sala de aula, utilizámos também a observação, que, segundo Laville e Dionne (2007), alerta o investigador para "conhecer bem o contexto em que vai operar e conhecer também os aspectos que deverão chamar a sua atenção no comportamento das pessoas" (p. 177). Seguindo os autores citados, preparámos um plano para observar em tempo real o campo da pesquisa, para perceber as ações e seu enquadramento, no que diz respeito ao processo de inclusão dos estudantes surdos e ao seu processo de aprendizagem. Pretendemos observar, para compreender, a relação e a comunicação dos estudantes surdos com o professor, com os colegas ouvintes e com o intérprete e, ainda, as estratégias utilizadas no seu processo de aprendizagem. Foram feitas três observações, de três horas cada (das 8 às 11 horas), em cada uma das três salas de aula, nove no total, correspondentes aos professores P1, P2 e P3, nas quais estavam "incluídos" os três estudantes surdos: ES1, ES2 e ES3.

Os fatos ocorridos foram registados em diário de campo, o mais próximo possível do acontecido, e depois organizados em grelha, incluindo os comentários/inferências que se julgaram necessários, de forma a constituírem um retrato "vivo" da situação observada, para depois ser analisada, tendo em conta um dos objetivos desta pesquisa: compreender o que os estudantes surdos "fazem" em sala de aula regular, no ensino superior, no curso de graduação em Pedagogia.

3. Apresentação, ANálise e DISCUSSÃO DOS RESULTADOS

Para a apresentação, análise e interpretação dos resultados, a informação foi organizada em duas grandes categorias: (i) o que pensam os estudantes surdos sobre o seu processo de inclusão e (ii) o que esses estudantes "fazem", na sala de aula regular.

\subsection{PERCEPÇÕES DOS ESTUDANTES SURDOS SOBRE O PROCESSO DE I N C L U S ÃO}

A informação obtida, relativamente ao que os estudantes surdos pensam sobre a sua inclusão na universidade, no curso de Pedagogia, encontra-se compilada na Tabela 1. Cada uma destas categorias está subdividida em subcategorias, resultantes da agregação das unidades de registo.

De acordo com a informação recolhida, os estudantes surdos conhecem o conceito de 
TA B E L A 1

Caraterização da Opinião dos Estudantes Surdos

\begin{tabular}{|c|c|c|c|c|}
\hline \multirow[t]{2}{*}{ Categorias } & \multirow{2}{*}{$\begin{array}{c}\text { Subcategoria } \\
\text { s }\end{array}$} & \multicolumn{3}{|c|}{ Unidades de registo } \\
\hline & & Estudante Surdo 1 & Estudante Surdo 2 & Estudante Surdo 3 \\
\hline \multirow[t]{3}{*}{$\begin{array}{l}\text { Processo de } \\
\text { inclusão dos } \\
\text { estudantes } \\
\text { surdos no } \\
\text { Ensino } \\
\text { Superior }\end{array}$} & $\begin{array}{l}\text { Conceito de } \\
\text { Inclusão }\end{array}$ & $\begin{array}{l}\text { "O que entendo sobre inclusão é que antigamente não } \\
\text { existia, não havia intérprete" } \\
\text { "ninguém sabia o que era. Não havia um conheci- } \\
\text { mento" } \\
\text { "Não conhecia o decreto que fala sobre inclusão" } \\
\text { "Hoje já conhecemos, já entendemos" } \\
\text { "Chegou o decreto, porque veio do governo e a presi- } \\
\text { dente aceitou" }\end{array}$ & $\begin{array}{l}\text { "Bom, antes não tinha } \\
\text { na sala de aula ouvin- } \\
\text { tes e surdos e hoje já } \\
\text { tem" }\end{array}$ & $\begin{array}{l}\text { "Para mim significa tanto o } \\
\text { surdo quanto o ouvinte está } \\
\text { no mesmo grau de estudo" }\end{array}$ \\
\hline & $\begin{array}{l}\text { Inclusão do } \\
\text { estudante } \\
\text { surdo no } \\
\text { ensino } \\
\text { superior }\end{array}$ & $\begin{array}{l}\text { "sobre inclusão dos surdos na sala de aula é muito } \\
\text { bom" } \\
\text { "mas há uma inclusão mais ou menos, precisa-se de } \\
\text { mais elaboração" } \\
\text { "o surdo ficava sozinho junto com ouvinte, não } \\
\text { aprendia muito" } \\
\text { "Depois chegou o intérprete e ajuda a trocar informa- } \\
\text { ções" } \\
\text { "Hoje há uma troca de experiência com os ouvintes" } \\
\text { "Aqui na faculdade há mais ou menos inclusão" } \\
\text { "hoje os alunos conseguem formar grupos com os } \\
\text { surdos com a ajuda do intérprete" }\end{array}$ & $\begin{array}{l}\text { "Significa um estudo } \\
\text { mais aprofundado" } \\
\text { "Eu penso que em sala } \\
\text { de aula é dificil" } \\
\text { "precisa ter paciência" }\end{array}$ & $\begin{array}{l}\text { "Para mim significa tanto o } \\
\text { surdo quanto o ouvinte está } \\
\text { no mesmo grau de estudo" } \\
\text { "Igual, o ouvinte e o surdo } \\
\text { evoluindo junto" }\end{array}$ \\
\hline & $\begin{array}{l}\text { Preferência } \\
\text { pela sala } \\
\text { especial }\end{array}$ & $\begin{array}{l}\text { "Eu preferia a sala só com alunos especiais" } \\
\text { "eu estudei em sala especial" } \\
\text { "mas depois chegou a inclusão e acabou as salas } \\
\text { especiais" }\end{array}$ & ------------------------- & $\begin{array}{l}\text { "Eu gosto mais de salas espe- } \\
\text { ciais em questão do aprendi- } \\
\text { zado" }\end{array}$ \\
\hline \multirow{5}{*}{$\begin{array}{l}\text { Processo de } \\
\text { ensino e } \\
\text { aprendizage } \\
\mathrm{m}\end{array}$} & $\begin{array}{l}\text { Comunicação } \\
\text { com os } \\
\text { professores }\end{array}$ & $\begin{array}{l}\text { "Bom, eu consigo me comunicar com ele" } \\
\text { "mas quando a comunicação dele vem até a mim há } \\
\text { uma barreira" } \\
\text { "precisa chamar o intérprete" } \\
\text { "aí sim, a comunicação acontece" }\end{array}$ & $\begin{array}{l}\text { "Através de gestos" } \\
\text { "às vezes LIBRAS" } \\
\text { "mostro as atividades a } \\
\text { eles" } \\
\text { "Através de bilhetes" } \\
\text { "com a ajuda do intér- } \\
\text { prete" }\end{array}$ & $\begin{array}{l}\text { "Eu sempre senti vergonha de } \\
\text { chegar perto, de fazer per- } \\
\text { guntas" } \\
\text { "sempre chamo o intérprete." } \\
\text { "[Comunico] Por gestos, pela } \\
\text { escrita, com o suporte do } \\
\text { intérprete" }\end{array}$ \\
\hline & $\begin{array}{l}\text { Participação } \\
\text { em sala de } \\
\text { aula }\end{array}$ & $\begin{array}{l}\text { "Eu sempre venho à faculdade" } \\
\text { "participo fazendo as atividades" } \\
\text { "e também bastante slides" } \\
\text { "Bem, quando há divisão de trabalho eu fíco só, não } \\
\text { chamo ninguém" } \\
\text { "os próprios ouvintes começam a se aproximar, então } \\
\text { se formam os grupos". } \\
\text { "gosto de organizar o grupo, fazer slides, mostrar } \\
\text { sugestões, perguntar se está certo, o português" }\end{array}$ & $\begin{array}{l}\text { "Eu sempre participo } \\
\text { fazendo as ativida- } \\
\text { des" } \\
\text { "fazendo slides" } \\
\text { "Reunimo-nos em gru- } \\
\text { po" } \\
\text { "Para me comunicar nos } \\
\text { grupos faço uso de } \\
\text { gestos" }\end{array}$ & $\begin{array}{l}\text { "Os grupos de ouvintes são } \\
\text { formados, mas não me sinto } \\
\text { a vontade de estar lá, eles só } \\
\text { falam e eu não entendo" } \\
\text { "Então o intérprete vem me } \\
\text { explicar e então dou opinião } \\
\text { e ele repassa para o grupo" }\end{array}$ \\
\hline & $\begin{array}{l}\text { Estratégias } \\
\text { utilizadas } \\
\text { pelos } \\
\text { professores }\end{array}$ & $\begin{array}{l}\text { "os professores falam: - Nossa! Excelente trabalho!" } \\
\text { "O professor explica e o intérprete traduz" } \\
\text { "o intérprete traduz realizamos as atividades e repas- } \\
\text { samos para ele" }\end{array}$ & ----------------------- & 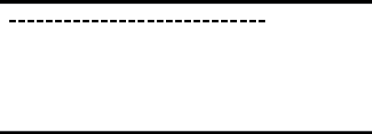 \\
\hline & $\begin{array}{l}\text { Relação e } \\
\text { comunicação } \\
\text { com os } \\
\text { colegas } \\
\text { ouvintes }\end{array}$ & $\begin{array}{l}\text { "Aqui no curso de pedagogia os alunos só vivem } \\
\text { falando sempre" } \\
\text { "quando querem perguntar ou saber de algo chamam } \\
\text { o intérprete" } \\
\text { "o intérprete colhe as informações e repassa e vice- } \\
\text { versa" } \\
\text { "Quando quero me comunicar com eles também uso } \\
\text { o intérprete como suporte dessa comunicação" }\end{array}$ & $\begin{array}{l}\text { "A relação com os meus } \\
\text { colegas é tranquila, } \\
\text { tenho amigos na sala } \\
\text { de aula" }\end{array}$ & "A relação é tranquila" \\
\hline & $\begin{array}{l}\text { Relação e } \\
\text { comunicação } \\
\text { com o } \\
\text { intérprete de } \\
\text { LIBRAS }\end{array}$ & $\begin{array}{l}\text { "Eu e o intérprete nós temos um relacionamento } \\
\text { bom" } \\
\text { "eu sou inteligente, ele também, então trocamos } \\
\text { muitas informações" } \\
\text { "Eu passo para ele e ele também me ajuda em alguns } \\
\text { sinais" } \\
\text { "Eu também o ajudo quando ele sinaliza algum sinal } \\
\text { errado eu o corrijo" }\end{array}$ & "Boa, ótima" & $\begin{array}{l}\text { "Ótima" } \\
\text { "Eu pergunto muito a ele" } \\
\text { "é importante porque ele faz a } \\
\text { intermediação do professor } \\
\text { para nós" }\end{array}$ \\
\hline
\end{tabular}


inclusão, significando, globalmente, para eles, a interação do estudante surdo e do estudante ouvinte. Os três estudantes gostam da proposta de inclusão, ou seja, gostam da ideia de surdos e ouvintes terem a possibilidade de conviverem/ estudarem juntos, nos mesmos espaços; porém, na prática, eles têm dificuldade em estar numa sala de aula onde o professor não está preparado para atuar com a surdez dos seus alunos. No entanto, percebemos que os estudantes surdos compreendem que, para haver inclusão, eles precisam de ficar nas salas regulares, tendo contato com os colegas ouvintes, intérprete e professor. Afirmam que existe uma tentativa de inclusão e não uma inclusão real. Apontam que a inclusão é difícil e que é preciso ter paciência. Dois dos estudantes surdos preferem as salas especiais porque a comunicação é feita através da LIBRAS, porque têm contato com outros estudantes surdos, porque o professor compreende a LIBRAS e, segundo o ES3, porque se aprende mais nas salas especiais. A legislação brasileira que regulamenta a proposta de inclusão dos surdos "obriga" à aprendizagem e utilização da LIBRAS e ao contato entre os estudantes surdos e ouvintes, mas os professores não têm formação para atuar com os estudantes surdos, gerando assim dificuldades.

Relativamente ao processo de ensino e aprendizagem dos alunos surdos, percebemos que existe uma barreira na comunicação entre os estudantes surdos e os professores, que a participação em sala de aula desses estudantes acontece a maior parte das vezes com a ajuda do intérprete, porque os professores só utilizam a oralidade; a comunicação dos estudantes surdos com os colegas ouvintes é realizada através de gestos e escrita, e com o intérprete é feita através da LIBRAS; a comunicação com os professores faz-se maioritariamente com o intérprete e através de gestos e de bilhetes escritos.
Quanto à participação em sala de aula, os estudantes surdos afirmam que participam nas aulas, realizando as atividades propostas. Integram os trabalhos de grupo, embora um não goste de estar nos grupos com os ouvintes e a maioria tenha dificuldade em comunicar com os colegas. Afirmam que vêm à faculdade, participam nas aulas, realizam as atividades e slides para os trabalhos de grupo; contudo, quando o intérprete não se encontra na sala, acabam por ir embora porque o professor não sabe comunicar. A instituição não tem a preocupação de colmatar as ausências do intérprete, o que diminui o estímulo para estudar e permanecer na sala de aula. Constata-se que, quando há divisão de grupos para fazer trabalho em sala de aula, o aluno surdo espera que os colegas ouvintes o chamem, não toma a iniciativa, mas a partir daí participa, dá opinião, pede a colaboração dos ouvintes para verificar se o português escrito está correto, apresenta para o grande grupo o trabalho realizado e, por vezes, organiza o grupo. Mesmo no pequeno grupo a comunicação é difícil, é utilizado o gesto, o que não é suficiente para uma comunicação eficaz e à-vontade dentro do grupo. Quando o intérprete está presente, explica o que o grupo está a discutir, o surdo dá a sua opinião e o intérprete de LIBRAS passa a informação para o grupo. Mesmo estando presente a dificuldade de comunicação nos grupos, os estudantes surdos gostam de participar no trabalho de grupo.

Na subcategoria "Estratégias utilizadas pelos professores", os resultados mostram que a maioria dos estudantes surdos não revelou as estratégias utilizadas pelos professores para a aprendizagem. Os três estudantes mencionam o intérprete de LIBRAS como interlocutor da aprendizagem, afirmando que os professores precisam de aprender LIBRAS para melhorar a prática em sala de aula. O ES1 ressalta que os 
professores elogiam o trabalho realizado por ele, que o professor explica e que o intérprete de LIBRAS realiza a tradução durante as aulas. O ES2 afirma que antes da chegada do intérprete não havia interação dos surdos com os professores; somente depois de este chegar é que passou a existir comunicação. O ES3 relata que os professores são bons, citando os de matemática e didática, mas quando tem dúvidas pergunta ao intérprete de LIBRAS. Nota-se, pelo relato dos estudantes surdos, que o intérprete é um profissional necessário para que a comunicação aconteça em sala de aula. É necessário ter condições e meios que promovam a comunicação entre os estudantes surdos e os professores e dos estudantes surdos com os ouvintes.

No que se refere à subcategoria "Relação e comunicação com o intérprete de LIBRAS”, os três estudantes afirmam que têm um relacionamento bom/ótimo com o intérprete, que trocam muitas informações com ele e que é o intérprete que faz a comunicação entre o surdo e o professor. A relação e comunicação dos três estudantes surdos com os colegas ouvintes faz-se por meio do intérprete, com gestos e com escrita, e a relação com os colegas ouvintes é bem tranquila, acontecendo, na maioria das vezes, por meio da mediação do intérprete.

Esta presença tão forte do intérprete, na dinâmica de todo o processo, pode levar à confusão entre os papéis do professor e do intérprete. A legislação responsabiliza o professor por todo o processo de aprendizagem dos estudantes ouvintes e estudantes surdos, sendo que $o$ intérprete apenas fornece $o$ auxílio na comunicação entre estudantes surdos e professores e entre estudantes surdos e estudantes ouvintes.

\subsection{O QUE OS ESTUDANTES SURDOS FAZEM NA SALA DE AULA}

Decorrente das observações realizadas em sala de aula, apresenta-se a Tabela 2, com duas categorias, divididas em subcategorias, onde se podem observar os comportamentos dos estudantes surdos em relação aos professores e aos colegas.

Os resultados para a categoria processo de aprendizagem dos estudantes surdos apontam que os surdos se esforçam para comunicar com os professores e com os colegas ouvintes, mas ainda há uma barreira devido ao desconhecimento da LIBRAS, por parte dos professores e colegas ouvintes.

Observámos que o processo de aprendizagem dos estudantes surdos acontece por meio do intérprete e de gestos, ou não acontece, às vezes. Observa-se o esforço dos estudantes surdos para comunicarem e se relacionarem com os professores, mas, devido à falta de conhecimento da língua de sinais, por parte dos professores, esta relação e comunicação ficam difíceis. Um dos professores utiliza um pouco a LIBRAS, o que é motivo de alegria expressa de um dos surdos e um sinal da necessidade de formação em LIBRAS dos professores de surdos.

Constatámos que dois dos surdos observados comunicam e relacionam-se mais com os colegas ouvintes. Essa comunicação/relação dos estudantes surdos com os ouvintes acontece em sala de aula, por meio do intérprete; outras vezes surge espontaneamente com gestos, pois nenhum estudante ouvinte da turma conhece a LIBRAS. O ES1 é o que mais interage com os colegas ouvintes, seja por meio da escrita, dos gestos ou LIBRAS. Cumprimenta os colegas ouvintes, procuraos para mostrar as novidades, anda muito pela sala e conversa bastante. Insiste até os colegas ouvintes compreenderem o que ele 
TAB ELA 2

Caracterização do "Fazer" dos Estudantes Surdos nas Aulas

\begin{tabular}{|c|c|c|c|c|}
\hline \multirow[t]{2}{*}{ Categorias } & \multirow[t]{2}{*}{ Subcategorias } & \multicolumn{3}{|c|}{ Unidades de observação } \\
\hline & & Observação 1 & Observação 2 & Observação 3 \\
\hline \multirow[t]{4}{*}{$\begin{array}{l}\text { Processo } \\
\text { de } \\
\text { aprendiza } \\
\text { gem dos } \\
\text { alunos } \\
\text { surdos }\end{array}$} & $\begin{array}{l}\text { Relação e } \\
\text { comunicação } \\
\text { dos } \\
\text { estudantes } \\
\text { surdos com o } \\
\text { professor }\end{array}$ & $\begin{array}{l}\text { ES3 cumprimenta P1 que responde } \\
\text { oralmente } \\
\text { ES1 pede licença e faz suas pergun- } \\
\text { tas a P1 e o intérprete traduz } \\
\text { ES1, por sua vez, faz sinal de que } \\
\text { entendeu } \\
\text { ES3 pede para o intérprete perguntar } \\
\text { sobre os prazos da entrega dos } \\
\text { relatórios a P1 } \\
\text { ES3 parece não gostar de tirar dúvi- } \\
\text { das com os professores } \\
\text { ES1 afirma que está contente porque } \\
\text { P3 demonstra saber um pouco da } \\
\text { LIBRAS }\end{array}$ & $\begin{array}{l}\text { ES1 abraça P1, enquanto este orienta } \\
\text { uma estudante } \\
\text { ES2 parece não perceber o que se } \\
\text { passa na sala de aula } \\
\text { P2 não se dirige a ES2 para tentar } \\
\text { comunicar } \\
\text { Passados mais alguns minutos, ES2 } \\
\text { ausenta-se da sala, sem se comu- } \\
\text { nicar com P2 }\end{array}$ & $\begin{array}{l}\text { ES3 responde a P3 afirmando que o } \\
\text { trabalho com listas pode ser feito } \\
\text { desde a educação infantil podendo ser } \\
\text { de frutas, brinquedos preferidos, festa } \\
\text { de aniversário, entre outros } \\
\text { ES1 e ES2 afirmam a P3 que compreen- } \\
\text { deram a importância de um trabalho } \\
\text { que promova a leitura e a escrita } \\
\text { desde a educação infantil } \\
\text { P3 dá os parabéns e volta ao grande } \\
\text { grupo }\end{array}$ \\
\hline & $\begin{array}{l}\text { Relação e } \\
\text { comunicação } \\
\text { dos } \\
\text { estudantes } \\
\text { surdos com } \\
\text { os colegas } \\
\text { ouvintes }\end{array}$ & $\begin{array}{l}\text { ES1 se dirige à turma (...) e cumpri- } \\
\text { menta todos com um bom dia em } \\
\text { LIBRAS } \\
\text { ES2 e ES3 formaram um grupo com } \\
\text { o intérprete e com alguns estu- } \\
\text { dantes ouvintes } \\
\text { Os estudantes surdos estão nos } \\
\text { grupos interagindo com } 2 \text { (dois) } \\
\text { colegas ouvintes e o intérprete de } \\
\text { LIBRAS }\end{array}$ & $\begin{array}{l}\text { ES1 comunica-se com todos os } \\
\text { colegas da sala, fica com o telefo- } \\
\text { ne em mãos a maior parte do } \\
\text { tempo, circula pela sala } \\
\text { ES1 circula pela sala interagindo } \\
\text { com os colegas ouvintes por meio } \\
\text { de gestos, LIBRAS e escrita } \\
\text { Já por volta das 09h15min chega } \\
\text { ES2, cumprimenta alguns cole- } \\
\text { gas, senta-se numa cadeira na } \\
\text { parte da frente da sala, olha para } \\
\text { todos os lados e percebe que o } \\
\text { intérprete não está } \\
\text { P3 prossegue formando } 2 \text { grupos } \\
\text { para o jogo de perguntas e respos- } \\
\text { tas, sendo que } 1 \text { grupo são os } \\
\text { piagetianos que irão realizar } \\
\text { perguntas sobre Piaget e mais } 1 \\
\text { grupo fará perguntas sobre } \\
\text { Vygotsky } \\
\text { ES1, ES2 e ES3 encontram-se no } \\
\text { grupo dos vygotskyanos e o intér- } \\
\text { prete também. Estes estão intera- } \\
\text { gindo com os colegas ouvintes e } \\
\text { dão opiniões para as perguntas }\end{array}$ & $\begin{array}{l}\text { ES1 cumprimenta os colegas } \\
\text { ES1 conversa um pouco com os colegas } \\
\text { ouvintes e apresenta o colega surdo } \\
\text { que veio com ele } \\
\text { ES1 chega à sala de aula, abraça P2 e } \\
\text { pede para dar um aviso aos colegas } \\
\text { antes que a turma saia. ES1 avisa } \\
\text { sobre o curso de LIBRAS da associa- } \\
\text { ção de surdos de que faz parte e diz } \\
\text { que as inscrições estão abertas } \\
\text { O intérprete realiza a interpretação das } \\
\text { falas de ES2 enquanto ES1 conversa } \\
\text { com alguns colegas ouvintes, por } \\
\text { meio da escrita e de gestos } \\
\text { Na formação dos grupos os estudantes } \\
\text { surdos estão juntos com o intérprete e } \\
\text { alguns colegas ouvintes } \\
\text { ES1 conversa com alguns colegas ouvin- } \\
\text { tes, por meio da escrita e de gestos }\end{array}$ \\
\hline & $\begin{array}{l}\text { Relação e } \\
\text { comunicação } \\
\text { dos } \\
\text { estudantes } \\
\text { surdos com o } \\
\text { intérprete }\end{array}$ & $\begin{array}{l}\text { Os estudantes surdos seguem a } \\
\text { interpretação realizada pelo intér- } \\
\text { prete de LIBRAS, estão sentados } \\
\text { bem próximos, nas cadeiras, de } \\
\text { frente para o intérprete } \\
\text { ES3 pede para o intérprete perguntar } \\
\text { sobre os prazos da entrega dos } \\
\text { relatórios } \\
\text { ES2 e ES3 estão interagindo com o } \\
\text { intérprete, conversando também } \\
\text { sobre gestão } \\
\text { ES2 e ES3 acompanham a aula por } \\
\text { meio do intérprete }\end{array}$ & $\begin{array}{l}\text { ES2 passa o tempo inteiro à espera } \\
\text { do intérprete para comunicar algo } \\
\text { e sempre que é necessário oraliza } \\
\text { ES2 pede para o intérprete tirar uma } \\
\text { dúvida com P1; o intérprete, por } \\
\text { sua vez, chama P1 e faz a pergun- } \\
\text { ta de ES2 e traduz a resposta para } \\
\text { a esta estudante } \\
\text { ES3 pergunta ao intérprete as suas } \\
\text { dúvidas e este esclarece }\end{array}$ & $\begin{array}{l}\text { ES2 cumprimenta a todos com um bom } \\
\text { dia em LIBRAS, abraça o intérprete e } \\
\text { senta-se perto do mesmo } \\
\text { Este permanece sentado e começa a } \\
\text { interpretar a aula para ES2 }\end{array}$ \\
\hline & $\begin{array}{l}\text { Estratégias } \\
\text { utilizadas } \\
\text { pelos } \\
\text { estudantes } \\
\text { surdos no seu } \\
\text { processo de } \\
\text { aprendizagem }\end{array}$ & $\begin{array}{l}\text { Os estudantes surdos olham para o } \\
\text { ecrã e intérprete } \\
\text { ES1 levanta a mão e pede a palavra } \\
\text { ES1 diz que os conceitos de letra- } \\
\text { mento e alfabetização não estão } \\
\text { claros, e pede para P3 explicar } \\
\text { novamente }\end{array}$ & $\begin{array}{l}\text { ES1 levanta o braço, põe-se de pé e } \\
\text { pede a vez para comentar o vídeo } \\
\text { O intérprete realiza toda a tradução } \\
\text { para P2 e para os colegas ouvintes } \\
\text { Os surdos, junto com o intérprete, } \\
\text { fazem a leitura em LIBRAS } \\
\text { ES1 levanta a mão e faz uma per- } \\
\text { gunta a P3 } \\
\text { ES1 agradece a explicação e afirma } \\
\text { que entendeu } \\
\text { ES2 ressalta que a teoria da aprendi- } \\
\text { zagem proposta por Vygotsky } \\
\text { leva em consideração o contato da } \\
\text { pessoa com o meio e com o grupo } \\
\text { P3 concorda com a afirmação de } \\
\text { ES2 } \\
\text { ES1, ES2 e ES3 encontram-se no } \\
\text { grupo dos vygotskyanos e o intér- } \\
\text { prete também } \\
\text { Estes interagem com os colegas } \\
\text { ouvintes e dão opiniões para as } \\
\text { perguntas }\end{array}$ & $\begin{array}{l}\text { ES1 levanta a mão, pede a vez e põe-se } \\
\text { em pé, de frente para a turma } \\
\text { O intérprete traduz para P2 e para os } \\
\text { colegas ouvintes } \\
\text { P2 interage o o intérprete traduz } \\
\text { ES1 ressalta que o professor precisa } \\
\text { organizar métodos diferenciados para } \\
\text { que o estudante aprenda } \\
\text { ES1 levanta a mão e comenta o vídeo } \\
\text { dizendo que as pessoas enfrentam } \\
\text { dificuldades, pessoas com deficiência } \\
\text { física, pessoas que fazem hemodiálise, } \\
\text { o importante é o apoio } \\
\text { ES1 diz receber muito apoio } \\
\text { Toda a turma aplaude ES1. Em seguida, } \\
\text { P2 elogia ES1 } \\
\text { ES2 faz a leitura das imagens do vídeo } \\
\text { ES1 levanta o braço, põe-se de pé e pede } \\
\text { a vez para comentar o vídeo } \\
\text { O intérprete realiza toda a tradução para } \\
\text { P2 e para os colegas ouvintes } \\
\text { ES1 diz que o vídeo é igual à escola, um } \\
\text { precisa estar em diálogo com o outro, } \\
\text { buscando alternativas para as soluções } \\
\text { dos problemas }\end{array}$ \\
\hline
\end{tabular}


diz. Esta comunicação é bastante importante no processo de inclusão e os colegas ouvintes gostam dessa interação.

$\mathrm{Na}$ relação/ interação e comunicação dos estudantes surdos com o intérprete, constatamos que estes estão atentos à interpretação realizada pelo intérprete de LIBRAS. Percebe-se que os estudantes dependem totalmente deste profissional para comunicar dentro da sala de aula. Estão sempre junto ao intérprete, observa-se respeito, amizade e à-vontade na relação, talvez porque já estão juntos há quatro anos. Observando a forma como os estudantes surdos "falam" com o intérprete e a maneira como este lhes devolve a informação, i.e., quando fazem perguntas ao professor, podemos afirmar que os estudantes surdos confiam e estão seguros em relação ao que este lhes transmite. É visível a relação amigável entre estudantes surdos e intérprete de LIBRAS. Os estudantes surdos sentem-se à vontade, chamam-no para perguntar, tirar dúvidas e conversar com o professor. Quando o intérprete não está presente, os estudantes surdos não se sentem à vontade na sala de aula.

Constata-se que estes estudantes participam das aulas e promovem as suas aprendizagens, interagindo, fazendo perguntas, tirando dúvidas, utilizando material impresso e visual, discutindo no grande grupo e em pequenos grupos, mas quase sempre com a ajuda do intérprete. Utilizam, maioritariamente, a LIBRAS para a comunicação, o que os distancia dos colegas ouvintes e dos professores.

Os resultados revelam a dificuldade da comunicação no processo de ensinoaprendizagem, dificultando a participação dos estudantes surdos, que muitas vezes se retraem ou ficam inibidos em participar das diversas atividades. O interessante é que a relação e a comunicação entre estudantes surdos e estudantes ouvintes acontecem, pois uns e outros encontram maneiras de comunicarem e de se relacionarem.

\subsection{Discuss Ão DOS RESUltados}

Para uma melhor compreensão do processo de inclusão dos estudantes surdos, confrontámos os resultados obtidos neste estudo com os resultados encontrados pelos autores dos estudos referenciados no enquadramento teórico e com a legislação vigente no Brasil, agrupando-os em dois grandes enfoques: (i) as percepções dos estudantes surdos e (ii) o"fazer" dos estudantes surdos na sala de aula.

(I) AS PERCEPÇÕES DOS ESTUDANTES $S U R D O S$

Os estudantes surdos conhecem o conceito de inclusão, afirmando que a mesma se dá pela interação entre surdo e ouvinte, sendo pautada na lei, havendo documentos que a fundamentam. As suas reflexões vão ao encontro do que diz a Lei brasileira n. $^{\circ}$ 9.394/96, Lei de Diretrizes e Bases da Educação Nacional (LDBEN), na redação dada pela Lei $n^{\circ} 12.796$, de 2013, art $^{\circ} 59$, onde se afirma:

Os sistemas de ensino assegurarão aos educandos com deficiência, transtornos globais do desenvolvimento e altas habilidades ou superdotação: I - currículos, métodos, técnicas, recursos educativos e organização específicos, para atender às suas necessidades.

Percebemos que os estudantes surdos ainda não se sentem incluídos na sala de aula, destacando pontos desafiadores que fazem do processo de inclusão um caminho a percorrer, no sentido de uma Educação para Todos, indo ao encontro da afirmação de Sanches (2005):

A mudança geradora de uma educação inclusiva é um dos grandes desafios da 
educação de hoje porque imputa à escola a responsabilidade de deixar de excluir para incluir e de educar a diversidade dos seus públicos, numa perspectiva de sucesso de todos e de cada um, independentemente da sua cor, raça, cultura, religião, deficiência mental, psicológica ou física. (p. 128)

Compreendemos que a educação inclusiva é um desafio para as instituições de ensino superior, pois é necessário pensar em cada estudante, em cada surdo, no modo como cada um aprende, quais são as necessidades encontradas, para assim poder atuar. A educação inclusiva requer uma mudança geradora nas instituições de ensino, sendo necessário atender às diferenças.

Estes estudantes frequentaram as salas especiais e afirmam que esta experiência foi melhor do que a que estão a experimentar na sala com estudantes ouvintes, sobretudo pela dificuldade de comunicação com os pares ouvintes e professores. As universidades são compostas em sua maioria por estudantes ouvintes, o que reforça a cultura ouvinte, indo ao encontro do que afirmam Bisol et al. (2010) sobre os desafios que os estudantes surdos enfrentam no ensino superior: participar e incluir-se numa comunidade em que a comunicação oral, que não é a sua, é a principal, muitas vezes única, forma de comunicar.

Os professores não conhecem a LIBRAS, pelo que a comunicação com os estudantes surdos é muito limitada. Estes utilizam o intérprete como suporte desta comunicação e outras estratégias de comunicação, como a escrita e gestos, mas denunciam que sentem vergonha de comunicar com os professores ou fazer perguntas. O ponto-chave para que a comunicação aconteça é a presença da LIBRAS. É a primeira língua das pessoas surdas e precisa ser utilizada nas instituições.

A comunicação com os colegas ouvintes é tranquila, mas não eficaz, pois comunicam, essencialmente, através do intérprete. Nesta perspetiva, Marcon (2012) ressalta que

o tradutor/intérprete de Libras é o profissional que interpreta e traduz a mensagem de uma língua para outra de forma precisa, permitindo a comunicação entre duas culturas distintas. Ele possui, assim, a função de intermediar a interação comunicativa entre o surdo e a pessoa que não usa a Libras. (p. 237)

Compreende-se a importância e necessidade deste profissional, na comunicação entre surdos e ouvintes, pois sem ele há uma barreira na comunicação. A relação e a comunicação com o intérprete de LIBRAS é ótima, conforme eles afirmam e nós pudemos constatar, talvez devido ao importante suporte que este profissional oferece para a comunicação. Existe uma boa relação entre os estudantes surdos pesquisados e o intérprete, em função da boa e fluente comunicação através da LIBRAS. Este resultado aponta, mais uma vez, para a necessidade da presença do profissional intérprete de LIBRAS na educação de surdos.

As reflexões apresentadas pelos estudantes surdos mostram que eles compreendem os seus direitos e a ideia da inclusão, mas questionamna, apontando como principal entrave para a inclusão a falha na comunicação entre eles, os professores e os colegas ouvintes, devido ao não conhecimento dalíngua de sinais. Os estudantes surdos participam nas aulas realizando as atividades propostas pelos professores. Os grupos de trabalho são formados por surdos e ouvintes, o que é importante para a socialização das aprendizagens; contudo, nem todos se sentem à vontade no grupo com os ouvintes, precisamente porque a comunicação é difícil. Assim, é necessária uma melhor organização do ensino e da aprendizagem, conforme afirma Silva (2008): "em função de todos os 
alunos, para além de estarem sensibilizados à questão da diferença, independentemente da sua etiologia, sentirem-se confiantes quanto à(s) resposta(s) que podem pôr em prática" ( $\mathrm{p}$. 480).

A estratégia mais utilizada pelos professores é a oralidade, seja para explicar as matérias, seja para incentivar os alunos. O intérprete traduz as explicações dos professores. Os professores necessitam selecionar e trabalhar com estratégias de ensino que mais se aproximem e contemplem a aprendizagem e participação dos estudantes surdos nas aulas, tal como apontam Gonçalves e Festa (2013), a propósito das estratégias e métodos de ensino para estudantes surdos:

A presença do aluno Surdo em sala exige que o professor reconheça a necessidade da elaboração de novas estratégias e métodos de ensino que sejam adequados à forma de aprendizagem deste aluno Surdo. O aluno Surdo está na escola, então cabe aos professores criar condições para que este espaço promova transformações e avanços a fim de dar continuidade a um dos objetivos da escola, ser um espaço que promove a inclusão escolar. (p. 2)

\section{(Ii) O Que FAZEM os estudantes} SURDOS NA SALA DE AULA

A observação do processo de aprendizagem dos alunos surdos permitiu-nos verificar que há relação e comunicação dos estudantes surdos com o professor, quando se observa um surdo a abraçar um dos professores, ou quando aquele fica contente porque um dos professores sabe um pouco da LIBRAS. Porém, também acontece que, por vezes, o surdo parece não perceber o que se está a passar na sala de aula e, simplesmente, sai da sala. A relação e a comunicação podem-se esgotar no cumprimento ao professor, se toda a interação for mediada pelo intérprete. O impasse, a barreira nesta relação e comunicação é a falta de conhecimento, por parte dos professores, da LIBRAS, mas parece-nos que não se esgota aí. A verdadeira comunicação só acontecerá quando todos os interlocutores dominarem a língua em que se expressam, o que neste caso está longe de acontecer. Entendemos que a aprendizagem da LIBRAS necessita ser objeto de investigação e de valorização, por parte da comunidade ouvinte, dentro da qual destacamos os professores, quando se trata do processo de ensino e de aprendizagem dos estudantes surdos.

Os estudantes surdos relacionam-se e comunicam com os colegas ouvintes, principalmente nos grupos de trabalho, sendo que o intérprete ajuda nesta comunicação; o telemóvel também se mostrou, nas observações realizadas, um bom auxiliar na comunicação, o que não tinha sido observado nos estudos analisados, a par das imagens e da escrita, assim como dos gestos. É perceptível a hegemonia da cultura oralista nesta relação e comunicação, como afirma Arcoverde (2011): “a língua majoritária (oral), em meio às linguagens sociais existentes, é postulada como de maior envergadura e alcance social, sendo por isso imposta pela comunidade majoritária como língua maior" (p. 124).

A relação e comunicação dos estudantes surdos com o intérprete, na sala de aula é boa/muito boa, sendo que eles dependem do intérprete para comunicar. Quando o intérprete não está, alguns estudantes saem. Estes resultados fazem-nos refletir, mais uma vez, sobre a importância que o intérprete tem na mediação da comunicação com os surdos, não só no processo de aprendizagem académica, mas também na socialização e na organização da sua vida futura.

Foi observado que os estudantes surdos participam nas aprendizagens desenvolvidas 
em sala de aula, dando opiniões, fazendo comentários, acompanhando os vídeos, as apresentações em power point, uns mais que outros, mas os três estudantes participam nos grupos e ajudam em alguns momentos os colegas, construindo estratégias próprias para aprender, perceber e ver o mundo - o que chamamos de cultura surda:

Cultura surda é o jeito de o sujeito surdo entender o mundo e de modificá-lo a fim de torná-lo acessível e habitável, ajustando-o com as suas percepções visuais, que contribuem para a definição das identidades surdas e das "almas" das comunidades surdas. Isso significa que abrange a língua, as ideias, as crenças, os costumes e os hábitos do povo surdo. (Strobel, 2016, p. 29)

Os resultados referentes ao "fazer" dos estudantes surdos sobre a sua inclusão no curso de Pedagogia revelaram que os surdos procuram participar nas diversas atividades propostas pelos professores em sala de aula; porém, esse processo de ensino-aprendizagem em muitos momentos acaba sendo excludente, pela barreira na comunicação e pela desvalorização da cultura surda.

Os grandes desafios que se colocam à instituição de ensino superior estudada, segundo os resultados desta pesquisa, são o recrutamento efetivo de intérpretes de LIBRAS, para assegurar a interpretação nas aulas, a tempo inteiro, a exigência de domínio efetivo da LIBRAS aos professores que trabalharem com surdos e a dinamização de cursos de LIBRAS, para ouvintes.

\section{CONSIDERAÇÕES FINAIS}

Este estudo propôs-se compreender o que os estudantes surdos pensam e fazem na sala de aula para a sua inclusão no curso de graduação em Pedagogia (ensino superior). Ficou evidente que os estudantes surdos, participantes da pesquisa, concordam que os surdos aprendam nas instituições onde estudam os ouvintes (o que usualmente é chamado de inclusão), conhecem os documentos que procuram implementar este processo, entendem o sentido e a proposta da mesma, mas questionam-na. Estes estudantes destacam que na instituição de ensino superior (campo da pesquisa) ainda não há inclusão, pois a comunicação e a interação com os ouvintes faz-se, essencialmente, através do intérprete. Apesar das barreiras ainda existentes, afirmam que a inclusão dos surdos na sala de aula regular é algo muito bom, mas preferem as salas especiais para a aprendizagem, pois para eles a aprendizagem acontece pela comunicação através da LIBRAS e pela relação com os colegas surdos, o que suporta o dizer de Sanches (2011a), ao afirmar que a educação inclusiva "é um processo, uma caminhada com avanços e recuos, com obstáculos a vencer, e não algo acabado, o 'farol' da participação ativa de todos, descobrindo e ativando o potencial de cada um" (p. 137).

Estes estudantes trabalham para a sua própria inclusão: participam nas aulas e nos trabalhos realizados em grupo, esforçam-se para aprender, procuram estar junto ao intérprete para melhor compreender tudo o que é proposto pelos professores, buscam a interação com os professores e colegas ouvintes, o que faz deles parte ativa da aula. A maior barreira existente entre eles, o desconhecimento da língua de sinais, por parte dos ouvintes, não os impede de trabalhar, quando mediados pelo intérprete e, com menos eficácia, na sua ausência. Embora o intérprete possa ser a mediação necessária para que a aprendizagem, a comunicação e a relação aconteçam, não pode ser a panaceia para resolver a interação entre os surdos e os ouvintes, pela inviabilidade da presença do intérprete em todas as situações de vida 
dos surdos e pela restrição à privacidade dos mesmos. Como foi verificado neste estudo, há mais formas de comunicação para além da LIBRAS que é preciso explorar, generalizar e tornar mais eficientes.

A LIBRAS é a primeira língua dos surdos, a sua forma de comunicar mais eficiente. Contudo, será sempre limitada, dado o reduzido número de pessoas, para além dos surdos, que a dominam, e, por isso, o desafio será encontrar alternativas ao uso exclusivo da LIBRAS. Por enquanto, será uma utopia (quem sabe se realizável?) pôr uma comunidade inteira a usar a LIBRAS. Por outro lado, os surdos também têm de se esforçar, em vez de se isolarem, para encontrar outras formas de comunicar com os ouvintes. Não é desejável promover a criação de comunidades fechadas, seja por que motivo for.

Este artigo pretende dar visibilidade a um problema que é dos surdos e dos que com eles partilham espaços e tempos, alertar os gestores escolares para a necessidade de dinamização de programas de aprendizagem da LIBRAS, para ouvintes e surdos, e sua utilização em meio escolar, e, também, assegurar que nenhum surdo deixe de aceder à escolarização (inicial, média ou superior) por falta de intérprete.

\section{REFERÊ NCI A S}

Ansay, N. (2009). A trajetória escolar de alunos surdos e a sua relação com a inclusão no ensino superior (Dissertação de mestrado). Universidade Federal do Paraná, Brasil.

Arcoverde, R. (2011). Dos desencontros com a linguagem escrita a um encontro plurilinguístico. In A. Dorziat (Org.), Estudos surdos: Diferentes olhares (pp. 105139). Porto Alegre: Mediação.

Bardin, L. (2006). Análise de conteúdo. Lisboa: Edições 70.

Bisol, C., Valentini, C., Simioni, J., \& Zanchin,
J. (2010). Estudantes surdos no ensino superior: Reflexões sobre a inclusão. Caderno de pesquisa, 40(139), 147-172.

Brasil. Ministério da Educação. Secretaria de Educação Especial no Brasil. (2006). Evolução da Educação Especial no Brasil. Recuperado em 13 maio, 2017, de http:// portal.mec.gov.br/seesp/arquivos/pdf/ brasil.pdf

Colaço, C., \& Sanches, I. (2013). Gerir a diversidade: Contributos da aprendizagem cooperativa para a construção de salas de aula inclusivas. Revista Portuguesa de Educação, 26(1), 307-347.

Correia, L. (2001). Educação inclusiva ou educação apropriada? In D. Rodrigues (Org.), Educação e diferença: Valores $e$ práticas para uma educação inclusiva (pp. 123-142). Porto: Porto Editora.

Correia, L. (2013). Inclusão e necessidades educativas especiais. Um guia para educadores e professores. Porto: Porto Editora.

Creswell, J. (2014). Investigação qualitativa e projeto de pesquisa: Escolhendo entre cinco abordagens. Porto Alegre: Penso.

Cruz, J., \& Dias, T. (2009). Trajetória escolar do surdo no ensino superior: Condições e possibilidades. Revista Brasileira Educação Especial, 15(1), 65-80.

Daroque, S. (2011). Alunos surdos no ensino superior: Uma discussão necessária (Dissertação de mestrado). Universidade Metodista de Piracicaba, Brasil.

Esteves, M. (2006). Análise de conteúdo. In J. Lima \& J. Pacheco (Orgs.), Fazer investigação. Contributos para a elaboração de dissertações e teses (pp. 105-126). Porto: Porto Editora.

Estrela, A. (1986). Teoria e prática de observação de classes. Uma estratégia de formação de professores. Lisboa: INIC.

Garcia, E. C. (2015). O que todo pedagogo precisa saber sobre LIBRAS: Os principais 
aspectos e a importância da Língua Brasileira de Sinais. Rio de Janeiro: Wak.

Gonçalves, H., \& Festa, P. (2013). Metodologia do professor no ensino de alunos surdos. Ensaios Pedagógicos. Revista Eletrônica do Curso de Pedagogia das Faculdades OPET, 6, $1-13$.

Laville, C., \& Dionne, J. (2007). A construção do saber: Manual de metodologia da pesquisa em ciências humanas. Porto Alegre: Artmed \& Belo Horizonte: Editora UFMG.

Marcon, A. (2012). O papel do tradutor/ intérprete de LIBRAS na compreensão de conceitos pelo surdo. ReVEL, 10(19), 233249.

Minayo, M. (Org.). (2009). Pesquisa social: Teoria, método e criatividade (28 $8^{\mathrm{a}}$ ed.). Petrópolis: Vozes.

Patatas, T., \& Sanches, I. (2017). Desafios da educação especial infantil em Angola. Revista Lusófona de Educação, 38, 63-79.

Quadros, R., \& Karnopp, L. (2004). Língua Brasileira de Sinais: Estudos linguísticos. Porto Alegre: Artmed.

Robert, A., \& Bouillaguet, A. (1997). L'analyse de contenu. Paris: PUF.

Sanches, I. (2005). Compreender, agir, mudar, incluir. Da investigação-acção à educação inclusiva. Revista Lusófona de Educação, 5, 127-142.

Sanches, I. (2011a). Do 'aprender para fazer' ao 'aprender fazendo': As práticas de educação inclusiva na escola. Revista Lusófona de Educação, 19, 135-156.

Sanches, I. (2011b). Em busca de indicadores de educação inclusiva. A "voz" dos professores de apoio sobre o que pensam, o que fazem e o que gostariam de fazer. Lisboa: Edições Universitárias Lusófonas.

Sanches, I., \& Teodoro, A. (2007). Procurando indicadores de educação inclusiva: As práticas dos professores de apoio educativo. Revista Portuguesa de Educação, 20(2), 105-
149.

Silva, M. (2008). Inclusão e formação docente. Eccos Revista Científica, 10(2), 479-498.

Silva, P. (2015). A inclusão do estudante surdo no ensino superior: Das percepções de estudantes surdos e seus professores às práticas de sala de aula. Estudo de caso (Dissertação de mestrado). Universidade Lusófona de Humanidades e Tecnologias, Lisboa, Portugal. Disponível em http://recil.grupolusofona. pt/bitstream/handle/10437/6904/ Disserta\%C3\%A7\%C3\%A30 Polliana. pdf? sequence $=1$

Stainback, S., \& Stainback, W. (1999). Inclusão: Um guia para educadores. Porto Alegre: Artmed.

Stake, R. (2011). Pesquisa qualitativa: Estudando como as coisas funcionam. Porto Alegre: Penso.

Strobel, K. (2016). As imagens do outro sobre a cultura surda. Florianópolis: Ed. da UFSC.

\section{LEGISLAÇÃ O CONSULTADA}

Lei n. ${ }^{\circ}$ 9.394, de 20 de dezembro de 1996. Lei de Diretrizes e Bases da Educação Nacional - LDBEN. Ministério da Educação. Brasília, Brasil. Recuperado em 27 maio, 2017, de http://portal.mec.gov.br/seed/arquivos/pdf/ tvescola/leis/lein9394.pdf

Lei 10.436, de 24 de abril de 2002. Dispõe sobre a Língua Brasileira de Sinais - Libras e dá outras providências. Recuperado em 30 maio, 2017, de http://www.planalto.gov.br/ ccivil 03/leis/2002/110436.htm

Lei $\mathrm{n}^{\circ}$ 12.796, de 4 abril de 2013. Altera a Lei no 9.394, de 20 de dezembrode 1996, que estabelece as diretrizes e bases da educação nacional, para dispor sobre a formação dos profissionais da educação e dar outras providências. http://www. in.gov.br/materia/-/asset publisher/ 
Kujrw0TZC2Mb/content/id/30037356/do12013-04-05-lei-n-12-796-de-4-de-abrilde-2013-30037348
THE INCLUSION OF DEAF STUDENTS IN HIGHER EDUCATION IN BRAZIL: THE CASE OF A PEDAgOgY COURSE

\section{Abstract}

The aim of this research is to understand the process of inclusion of deaf students in an undergraduate course in Pedagogy, in Brazilian higher education. To reach this goal, the techniques used were the semi-structured interview with three deaf students as well as the observation of three teachers' classes. It is a qualitative research, of a descriptive/ interpretative nature, that analyzes the subjects in their context and values the interaction that is established between them. Their perceptions show that deaf students understand the inclusion paradigm, its meaning and proposal, know the guiding documents, understand and agree with the principles and practices that are proposed, but they question it and claim to prefer special classes for learning. The observation showed that deaf students participate in class, work in groups, strive to learn, seek to be with the interpreter, to better understand, seek interaction with teachers and hearing colleagues, but point as a barrier to inclusion the ignorance of the sign language, on the part of the hearers. These students like the perspective of inclusion in socializing with hearers and try to contribute to this socialization and learning by using alternatives to sign language for communication. They point out, however, that it requires a collective effort, by deaf and hearing, to respect difference, identity and deaf culture in the school context.

KeYwords: Higher education; Deaf student; Inclusion; Brazil 
L'INCLUSION DE L'ÉTUDIANT SOURD DANS L'ENSEIGNEMENT SUPÉRIEUR : LE CAS D'UN COURS DE PÉdAgOGIE

\section{RÉSUMÉ}

Lobjectif de cette recherche est de comprendre le processus d'inclusion des étudiants sourds, dans le cours de Pédagogie, dans l'enseignement supérieur brésilien. Pour atteindre cet objectif, l'entretien semi-directif a été utilisé avec trois étudiants sourds et aussi l'observation des classes de trois enseignants de ces étudiants. Il s'agit d'une enquête qualitative, de nature descriptive/ interprétative, qui analyse les sujets dans leur contexte et valorise l'interaction qui s'établit entre eux. Par leurs opinions, on observe que les étudiants sourds comprennent le paradigme de l'inclusion, connaissent les documents d'orientation, approuvent les principes et les pratiques proposés, mais ils questionnent ses propositions et, pour leur apprentissage, ils préfèrent les classes spéciales. L'observation des classes a montré que les élèves sourds participent aux cours, au travail en groupe, ils font des efforts pour apprendre, sont proches de l'interprète pour mieux comprendre, cherchent l'interaction avec les enseignants et les autres collègues, mais il y a une barrière : l'ignorance de la langue signaux par les auditeurs. Ces étudiants aiment la perspective d'inclusion, au sein de l'institution, et demandent de l'aide pour y arriver, mais il faut un effort collectif des sourds et des auditeurs, de sorte que le respect de la différence, l'identité et la culture sourdes puissent être plus prononcés dans le contexte scolaire.

MotS-CLÉS : Enseignement supérieur ; Étudiant sourd ; Inclusion ; Brésil

\footnotetext{
${ }^{\text {I }}$ Centro de Estudos Interdisciplinares em Educação e Desenvolvimento (CeiED), Universidade Lusófona de Humanidades e Tecnologias, Portugal. ORCID: 0000-0001-8424-8780

${ }^{\text {II }}$ Faculdade Alpha, Recife, Brasil
} 